\title{
Conflitos entre governos subnacionais e o governo federal durante a pandemia de COVID-19: o Estado de São Paulo e \\ o caso da vacina CoronaVac
}

\author{
Conflicts between subnational governments and the federal \\ government during the COVID-19 pandemic: State of São Paulo \\ and the case of Corona Vac vaccine
}

\author{
Conflictos entre los gobiernos subnacionales y el gobierno \\ federal durante la pandemia COVID-19: el estado de São Paulo y \\ el caso de la vacuna Coronavac
}

Ana Tereza Lopes Marra de Sousa Docente da Universidade Federal do $A B C$ (UFABC) na graduação e pós-graduação em Relações Internacionais. Vice-coordenadora do Observatório de Política Externa e Inserção Internacional

(OPEB) da UFABC.

São Bernardo do Campo, São Paulo, Brasil

E-mail: ana.tereza@ufabc.edu.br Orcid: https://orcid.org/0000-0002-7580-4797

Gilberto Marcos Antonio Rodrigues

Docente da Universidade Federal do $A B C$ (UFABC) na graduação e pós-graduação em Relações Internacionais. Pesquisador Produtividade em Desenv. Tecnológico e Extensão Inovadora do CNPq. Membro do Observatório de Política Externa e Inserção Internacional (OPEB) da UFABC. São

Berardo do Campo, São Paulo, Brasil.

E-mail: g berto.rodrgues@ufabc.edu.br Orcid: https://orcid.org/0000-0001-5150-5146

\begin{abstract}
Resumo: Durante o governo Bolsonaro, mudanças radicais na Política Externa Brasileira (PEB), bem como o cenário de pandemia, têm atuado como motivadores de atividades paradiplomáticas que conflitam com orientações federais. Neste trabalho, a partir da análise da paradiplomacia do Estado de São Paulo (SP), especificamente no que se refere ao acordo com a Sinovac, visando testes e produção da vacina Corona $V a c$, o nosso objetivo será avaliar os fatores que explicam o conflito entre União e governo estadual. Argumentamos que mudanças na PEB direcionada à China, a falta de coordenação do governo federal para articular medidas de combate a pandemia, destacando-se o negacionismo científico do presidente, e disputas políticas são os principais fatores a explicar os choques entre SP e governo federal.
\end{abstract}

Palavras-chave: Paradiplomacia; Pandemia de COVID-19; China. 
Abstract: During the Bolsonaro government, radical changes in the Brazilian Foreign Policy (PEB), as well as the pandemic scenario, have acted as motivators for paradiplomatic activities that conflict with federal guidelines. In this work, from the analysis of the paradiplomacy of State of São Paulo (SP), specifically regarding the agreement with Sinovac, aiming at testing and producing Corona Vac vaccine, our objective will be to evaluate the factors that explain the conflict between the Union and state government. We argue that changes in PEB directed at China, the lack of coordination by the federal government to articulate measures to combat the pandemic, highlighting the president's scientific denialism, and political disputes are the main factors explaining the clashes between SP and the federal government.

Keywords: Paradiplomacy; COVID-19 pandemic; China.

Resumen: Durante el gobierno de Bolsonaro, cambios radicals en la Política Exterior Brasileña (PEB), as como el escenario pandémico, han actuado como motivadores de actividades paradiplomáticas que conflictan con los lineamientos federates. En este trabajo, a partir del análisis de la paradiplomacia del Estado de São Paulo (SP), especificamente en lo que respect al acuerdo con Sinovac, en aras de desarrollar y producir la vicuna CoronaVac, nuestro objetivo será evaluar los factors que explican el conflict entire Union y gobierno subnacional. Argumentamos que los cambios en la PEB dirigidos a China, la alta de coordinación port part del gobierno federal para articular medias de combated a la pandemia, subrayando el negacionismo científico del presidente, y las disputes políticas son los principles factors que explican los enfrentamientos entire SP y el gobierno federal.

Palabras clave: Paradiplomacia; Pandemia de COVID-19; China.

Recebido em 15/01/2021.

Aceito em 10/07/2021. 


\section{CONSIDERAÇÕES INICIAIS}

As drásticas mudanças na Política Externa Brasileira (PEB) operadas pelo governo de Jair Bolsonaro (2019-), bem como o cenário de pandemia de COVID-19, têm gerado incentivo para atividades de cooperação internacional de governos subnacionais - globalmente conhecidas como paradiplomacia - que conflitam com a União (SOUSA et al, 2020). Tal aspecto diferencia o momento da paradiplomacia no Brasil durante a pandemia das experiências das últimas décadas, uma vez que estas ocorreram de forma complementar e convergente - e, portanto, não conflituosa - com os esforços externos federais (VIGEVANI, 2006). Tem-se destacado a atuação internacional do Consórcio Nordeste (ARAÚJO; SILVA, 2020), do Consórcio Interestadual de Desenvolvimento Sustentável da Amazônia Legal (SANTORO, 2019), do Estado do Maranhão (ALVARENGA et al, 2020) e do Estado de São Paulo $(\mathrm{SP})^{1}$ (KHALIL, 2020), como casos em que é perceptível elementos de tensão entre governos estaduais e governo federal.

Neste artigo discutimos o emergente conflito entre os governos subnacionais e o federal nas relações internacionais. Para tanto, focaremos na análise da paradiplomacia realizada por São Paulo ${ }^{2}$. Destaca-se que foi público e notório o embate entre, de um lado, o governador de SP, João Dória (PSDB), e, de outro, o presidente Jair Bolsonaro (sem partido), envolvendo a parceria feita pelo Instituto Butantan com a empresa chinesa Sinovac, para teste e produção da vacina CoronaVac no Brasil, visando combater o novo coronavírus.

A partir da análise desse caso, o objetivo é avaliar os fatores que explicam o conflito entre União e governo estadual envolvendo a paradiplomacia. Tendo como base revisão bibliográfica e pesquisa em fontes primárias, argumentaremos que três elementos explicam esse conflito federativo: (i) a mudança na PEB promovida pelo Itamaraty na gestão de Ernesto Araújo (2019-2021), em especial no que diz respeito à China; (ii) no cenário da pandemia, a

\footnotetext{
${ }^{1}$ Durante o trabalho, trataremos o Estado de São Paulo pela sigla SP. Quando mencionada a cidade, seu nome será escrito na forma extensa "cidade de São Paulo".

${ }^{2} \mathrm{~A}$ escolha de São Paulo como estudo de caso do artigo se justifica pelo fato de ter uma relação direta com a China, o que possibilitou tanto a compra de equipamentos para a prevenção e tratamento da pandemia, quanto a compra e produção de vacina, por via de transferência de tecnologia por meio do Instituto Butantan - único instituto estadual que desenvolve pesquisas e produz vacinas para seres humanos em grande escala, com cerca de 100 anos de existência e reputação internacional.
} 
falta de coordenação central do governo federal, junto aos entes federados, para combater a COVID-19, destacando-se ainda o negacionismo científico do presidente, e; (iii) a competição política entre os atores que protagonizam o governo federal (Bolsonaro), de um lado, e a paradiplomacia dos governadores (com ênfase em Dória), de outro. Assim, afirmaremos que os governos subnacionais utilizam a paradiplomacia para exercer sua autonomia federativa em um cenário de crise humanitária, em que o conflito com a União se justifica na falta de coordenação federal para o combate à COVID-19.

Além desta introdução, este artigo conta com mais cinco partes. Na segunda, realizamos uma revisão de literatura sobre a paradiplomacia. Na terceira, revisamos como tem sido no Brasil a interação entre os governos subnacionais e o federal no que diz respeito às relações internacionais. Na quarta, destacamos a emergência de conflitos entre entes federados e governo federal na gestão Bolsonaro. Na quinta, apresentamos o estudo sobre a paradiplomacia de SP focando-se nas questões referentes ao acordo com a Sinovac. Na sexta, enfim, apresentamos nossas considerações finais.

\section{COOPERAÇÃO E CONFLITO ENTRE GOVERNOS SUBNACIONAIS E CENTRAIS NAS RELAÇÕES INTERNACIONAIS}

O tema da paradiplomacia está bastante consolidado na literatura das Relações Internacionais, inclusive no Brasil (PRADO, 2018). O termo foi definido por Soldatos (1993, p.46, tradução nossa) como sendo as atividades internacionais "realizadas diretamente por atores subnacionais (unidades federadas, regiões, comunidades urbanas, cidades), que apoiam, complementam, corrigem, duplicam ou desafiam a diplomacia do Estado-Nação". Para Keating (2001), razões culturais, políticas e econômicas apresentam-se como fundamentais para explicar a paradiplomacia.

Diversas são as formas por meio das quais se pode estruturar a inserção internacional subnacional - desde contatos esparsos até acordos de cooperação com o estabelecimento de compromissos e deveres - a depender dos limites imputados, em cada Estado, a ação 
subnacional (VIGEVANI, 2006) ${ }^{3}$. No que se refere a esse aspecto, em particular, uma parte da literatura tem se dedicado a refletir sobre as tensões e os conflitos potenciais que advêm da quebra do monopólio do governo central sobre a atividade diplomática, e os limites de atuação internacional dos governos subnacionais (DUCHACEK, 1990; RODRIGUES, 2008).

Cabe ressaltar que as visões mais tradicionais sobre política internacional partem da ideia de que o Estado detém o monopólio central das relações internacionais, em detrimento de atores não-estatais e não-centrais, sendo o único agente capaz de expressar um interesse nacional unificado e coerente na arena externa. Assim, dentro dessa visão, inicialmente a paradiplomacia foi vista por muitos governos centrais a partir de uma perspectiva conflitiva, dado representar risco à política externa pelo potencial de fragmentá-la, torná-la menos coerente e fragilizar a posição do Estado na arena internacional (MIKLOS, 2010).

Contudo, ao longo do tempo, alguns aspectos contribuíram para que a paradiplomacia passasse a ser vista de forma mais convergente aos esforços externos do governo central. Um deles foi o enquadramento dos conflitos mais radicais entre os governos centrais e subnacionais a partir do conceito da protodiplomacia (DUCHACEK, 1990) ${ }^{4}$. Outro, foi a acomodação e relativa integração, pelos governos centrais, da atividade internacional subnacional no conjunto das relações externas oficiais (MIKLOS, 2010). Aponta-se ainda que o foco da paradiplomacia em assuntos de baixa política e, portanto, com pouca capacidade de interferir em temas sensíveis, também é um aspecto que fez a paradiplomacia evoluir com baixa propensão de choque com o governo central (VIGEVANI, 2006).

Como destaca Costa (2013, p.53), entretanto, apesar de poucas, é possível encontrar menções a experiências em que prevaleceram tensões e conflitos, em que se destaca, dentre outros: a possibilidade de endividamento externo do ente subnacional como possível causa de desentendimento com o governo central; disputas entre governos subnacionais para a

\footnotetext{
${ }^{3}$ Não cabe neste artigo discorrer e explorar as variantes da paradiplomacia, tanto em relação às citadas razões expostas por Keating, quanto em relação a outras questões. Para uma visão mais diversa sobre o fenômeno ver o portal www.paradiplomacia.org e sua Revista TIP - Trabajos de Investigación em Paradiplomacia. Ver também o dossiê Fronteiras, Integração Regional e Paradiplomacia, Monções, V. 6, N. 12, 2017. Disponível em: https://ojs.ufgd.edu.br/index.php/moncoes/issue/view/255/showTo

${ }^{4}$ A protodiplomacia é apresentada como sendo um tipo de condução da atividade internacional ligada a movimentos secessionistas que visavam se estabelecer como entidades soberanas (DUCHACEK, 1990).
} 
recepção de investimentos externos, a força de Cidades Globais, enquanto centros que possuem dinâmica internacional própria, e limitações jurídicas à paradiplomacia como fontes de tensões com o governo central; e, ainda, diferenças político-partidárias entre os mandatários dos entes federados e do governo central como origem de possíveis choques.

Contudo, apesar de se apontar esses aspectos que podem ser objeto de tensão, como pontua a maior parte da literatura sobre paradiplomacia, os casos em que os conflitos ocorrem têm sido minoritários nas experiências analisadas. Assim, a visão mais difundida é a de que a relação entre governos subnacionais e centrais tem sido de forma geral caracterizada pela coordenação e cooperação quando ocorre a paradiplomacia 5 .

\section{O CENÁRIO NO BRASIL}

A interpretação de que a paradiplomacia não tem contraposto governos centrais e subnacionais também ganhou espaço nos estudos sobre inserção internacional das entidades subnacionais brasileiras. Destaca-se que os primeiros casos de paradiplomacia no país ocorreram na década de 1980. Contudo, o maior impulso veio com a redemocratização e a Constituição Federal de 1988, a partir da qual houve descentralização de atribuições que favoreceu governos estaduais e municipais, e o estabelecimento de competências comuns aos entes federados. Como aponta Rodrigues (2008), tais competência serviram como base para a atuação via paradiplomacia, ainda que ficasse garantido à União o monopólio das relações externas.

No país, as motivações de ordem econômica têm sido consideradas as mais fortes a justificar a paradiplomacia, destacando-se ações que visariam a captação de recursos no exterior, impulsionadas por restrições fiscais e orçamentárias existentes no cenário nacional e local, bem como com a finalidade de expansão das relações de comércio e investimento, e a busca de parceiros para cooperação técnica.

\footnotetext{
${ }^{5}$ Os autores utilizam o termo paradiplomacia em consonância com a literatura internacional sobre o tema, mas cientes de que parte da literatura e de operadores governamentais no Brasil e em outros países prefere a expressão cooperação internacional descentralizada para qualificar o mesmo fenômeno.
} 
Embora em um primeiro momento a paradiplomacia dos governos brasileiros não tenha sido bem assimilada pela estrutura da diplomacia central, Miklos (2010, p.50) destaca que a partir de 1995, buscou-se por meio da chamada "diplomacia federativa" "promover uma maior aproximação entre a Chancelaria e as unidades subnacionais brasileiras, incluindo a dimensão federativa no processo de construção da política externa brasileira". Em 1997 houve a criação da Assessoria de Relações Federativas (ARF) dentro do MRE para facilitar a interação com os Estados federados e municípios e, ainda, o estabelecimento de escritórios de representação do Itamaraty em várias capitais de Estados brasileiros (MIKLOS, 2010; BOGEA, 2001).

A partir do governo Lula, novas mudanças foram processadas nas relações entre diplomacia e paradiplomacia, uma vez que o governo central passou a pensá-la como uma dimensão que poderia favorecer iniciativas da política externa, em especial a cooperação sulsul (MIKLOS, 2010). A ARF passou a ser a Assessoria de Assuntos Federativos e Parlamentares (AFEPA), ampliando sua atuação. Criou-se ainda a Assessoria de Cooperação Internacional Federativa (ACIF), em 2003, e, sob a Presidência da República, a Subchefia de Assuntos Federativos (SAF), em 2004. Como afirma Costa (2013, p.50), a SAF tornou-se um importante "indutor de mudança no posicionamento do Itamaraty" com relação ao papel que a paradiplomacia poderia desempenhar como parte da política externa, "e para a legitimação da dimensão subnacional da política externa brasileira a partir de então".

Desse modo, a paradiplomacia no Brasil, com o passar do tempo, evoluiu para realizarse de forma convergente com esforços federais. Entretanto, apesar de poucos, há na literatura indicações de alguns casos em que ocorreram tensões entre governos subnacionais e União. Rodrigues (2019, p.1) lembra da atuação dos governadores Leonel Brizola, do Rio de Janeiro, e de Franco Montoro, de São Paulo, nos anos de 1980, em que ambos os políticos estabeleceram um contraponto a diplomacia oficial daquele momento histórico, e "por meio de seus contatos e prestígio internacionais, contribuíram para reinserir o Brasil no mundo sulamericano e multilateral".

Um caso mais recente, segundo Costa (2013), refere-se à atuação de SP e da cidade de São Paulo perante a 15aㅡ Conferência das Partes sobre Mudança do Clima (COP-15), em 2009, 
no qual foi possível perceber que a posição de tais entes subnacionais, a favor de metas mais ambiciosas de redução de Gases de Efeito Estufa (GEE), desafiou àquela inicialmente assumida pelo Itamaraty, mais conservadora. Tal disputa foi alimentada ainda por aquela que ocorria na arena eleitoral (em 2010 haveria eleição para presidente), na qual disputariam José Serra, governador paulista, e Dilma Rousseff, então Ministra Chefe da Casa Civil (COSTA, 2013).

Apesar dos casos citados, contudo, a interpretação geral era de que no Brasil a paradiplomacia havia sido convergente aos esforços externos do governo federal, uma vez que mesmo com a existência de tensões, elas teriam ocorrido dentro de um padrão de relacionamento - entre governo federal e subnacionais - que no geral foi cooperativo (COSTA, 2013).

\section{POTENCIAL CONFLITIVO ENTRE GOVERNOS SUBNACIONAIS E FEDERAL NA GESTÃO BOLSONARO}

Duchacek (1990) entende que o potencial de conflito entre governos subnacionais e centrais devido à paradiplomacia é condicionado pela capacidade de se promover uma coordenação entre as duas esferas para o estabelecimento da política externa. Há de se saber se essa capacidade de coordenação é capaz de gerar - ao final - uma política em que há a "percepção do Estado-Nação como um ator basicamente unívoco" (DUCHACEK, 1990, p. 29, tradução nossa), ainda que as políticas resultem de uma combinação entre interesses da diplomacia e paradiplomacia. O autor denomina de "política externa combinativa" o cenário em que prevalece a coordenação. Caso contrário, haveria um processo de fragmentação, duplicação ou competição entre o governo central e os entes subnacionais com impacto sobre a coerência da política externa, cenário o qual o autor chama de "segmentação competitiva cooperativa".

Pode-se então interpretar a partir dessa categorização que o cenário no Brasil nas últimas décadas se aproximou da ideia de "política externa combinativa": apesar de alguns episódios de conflito, a paradiplomacia foi relativamente convergente aos esforços federais. Contudo, a partir da vigência do governo de Jair Bolsonaro, alguns analistas têm apontado 
para o crescente potencial conflitivo entre governo federal e subnacionais (RODRIGUES, 2019; SOUSA et al., 2020). Nossa pesquisa identificou os seguintes elementos que explicam essas tensões: i) as mudanças promovidas pelo Itamaraty na PEB; ii) o cenário de pandemia, a partir de 2020, no qual acirrou-se o conflito federativo, devido à falta de coordenação central do governo federal para combater a COVID-19, destacando-se o negacionismo científico do presidente, e; iii) as disputas políticas domésticas.

\section{Efeitos da mudança da PEB sobre a paradiplomacia}

Ao lado dos aspectos econômicos, as mudanças promovidas na PEB pela gestão de Araújo são as mais citadas como elementos a justificar a radicalização da paradiplomacia. A fala do governador Rui Costa (PT), da Bahia, sobre as atividades internacionais do Consórcio Nordeste é clara nesse sentido:

\footnotetext{
Vamos continuar buscando parcerias internacionais para gerar emprego e desenvolvimento, com respeito e muita diplomacia. O Consórcio vai, portanto, na contramão do que tem feito o governo federal, que tem acumulado uma série de insucessos nas relações internacionais, corroendo o resto de imagem que o País ainda tem no exterior. No Consórcio vamos fazer uma agenda em favor do Brasil e em favor do Nordeste. (COSTA, 2019, grifo nosso).
}

O governador do Estado de São Paulo, João Dória, também demonstrou descontentamento com a diplomacia do governo Bolsonaro, afirmando que o país tem sido conduzido de "forma errática", o que tem prejudicado a imagem do Brasil no exterior (DÓRIA, 2020a, p.1).

A PEB do governo Bolsonaro tem sido caracterizada por uma série de mudanças com relação a governos anteriores e ao próprio acumulado histórico da diplomacia brasileira (MARINGONI et al., 2021). Foge ao escopo deste trabalho analisar profundamente essas mudanças, mas aponta-se que a PEB formulada por Araújo foi marcada por uma política de alinhamento com o governo de Donald Trump, dos EUA, crítico ao multilateralismo e as 
Organizações Internacionais, climático-negacionista, e antagônico a China - todos aspectos que foram incorporados à $\mathrm{PEB}^{6}$.

Alguns desses pontos têm sido especialmente questionados pelos governos subnacionais, impulsionando-os para uma paradiplomacia mais assertiva. Santoro (2019) argumenta que as questões ambientais e as relações com a China foram os temas em que surgiram as maiores discordâncias. No que se refere a política ambiental, Couto $(2020$, p.1) destaca que após o então ministro do Meio Ambiente, Ricardo Salles, anunciar em maio de 2019 que estava revisando as diretrizes do Fundo Amazônia, no qual Alemanha e Noruega eram os maiores financiadores, os governadores da Amazônia Legal "viram-se com problemas ambientais e projetos de preservação e desenvolvimento sustentável parados" devido a interrupção de desembolsos do Fundo. Tal fato os motivou, por meio do Consórcio da Amazônia Legal, a buscar diretamente interlocução com embaixadores estrangeiros. Em dezembro de 2020, o governador do Maranhão, Flávio Dino (PC do B), foi eleito presidente de tal Consórcio com a finalidade de, nas suas palavras, em entrevista a Jubé $(2020$, p. 1), fazer "essa diplomacia do consórcio com os países financiadores, vendo como avançar no plano interno para que eles concordem em retomar os financiamentos".

Contudo, foi nas relações com a China que potenciais conflitos entre diplomacia e paradiplomacia se tornaram mais visíveis. A China é a maior parceira comercial do Brasil desde 2009, tendo se transformado também em importante investidora no país nos últimos anos (SCHUTTE, 2020) ${ }^{7}$. No entanto, apesar de sua importância econômica, o governo Bolsonaro promoveu tensões nas relações entre os países. Entre os atores, com influência na PEB, críticos ao papel que a China desempenhava para o Brasil cita-se o Presidente Bolsonaro, o então

\footnotetext{
${ }^{6}$ Para uma visão ampla e multidimensional das mudanças operadas pela PEB de Bolsonaro, ver o acervo de artigos publicados pelo Observatório de Política Externa e Inserção Internacional do Brasil (OPEB) da UFABC, disponível em: http://opeb.org/

${ }^{7} \mathrm{Em} 2020$, dados de janeiro a novembro, mostram que a China foi destino de $33 \%$ das exportações brasileiras, origem de $21,9 \%$ das importações, e responsável por gerar $63,43 \%$ do superávit comercial (BRASIL, 2020). Cabe ressaltar que os países são ainda: parceiros estratégicos desde 1993; formam com Índia, Rússia e África do Sul o agrupamento BRICS desde 2009, no qual fundaram um Arranjo Contingente de Reservas e o Novo Banco de Desenvolvimento, e; são parceiros estratégicos globais desde 2012.
} 
chanceler Ernesto Araújo (MRE), a assessoria internacional da Presidência da República e os filhos de Bolsonaro, principalmente o deputado federal Eduardo Bolsonaro.

Em seus discursos, o então ministro Araújo deixou claro que Brasil e China possuíam identidades contrapostas, sugerindo que aprofundar as relações com ela seria "vender nossa alma", e que mesmo as relações comerciais bilaterais deveriam ser vistas de forma crítica, pois a ascensão da China a maior parceria do Brasil estaria associada a "um período de estagnação do Brasil" e a "um ciclo do Brasil com parceiros errados" (ARAÚJO, 2019). A partir de 2020, diante de um quadro na PEB de aprofundamento do alinhamento com os EUA, a China passou a ser colocada como uma opção excludente em favor de maior aproximação com o governo Trump, o que gerou uma série de crises nas relações bilaterais Brasil-China fabricadas pelos atores no governo que queriam justificar uma maior aproximação com os EUA.

Destaque deve ser dado às acusações - reproduzidas de Trump - proferidas pelo Deputado Federal e então presidente da Comissão de Relações Exteriores e de Defesa Nacional da Câmara dos Deputados, Eduardo Bolsonaro, contra a China e o Partido Comunista da China via redes sociais, criticando tanto o tratamento que o país deu à pandemia, como a possível participação de empresas chinesas nas redes de $5 \mathrm{G}^{8}$. Menciona-se ainda as declarações xenófobas promovidas pelo então Ministro da Educação, Abraham Weintraub, contra a China nas redes sociais. Importa notar que em nenhuma das crises provocadas por essas declarações, o MRE atuou para apaziguar as tensões nas relações bilaterais, o que contrastou com o comportamento de outras autoridades subnacionais e do Congresso Nacional, que se empenharam em buscar pacificação com as partes chinesas.

Pela importância que a China possui para o Brasil e pelo próprio potencial econômico que representa para os entes federados, vários governos subnacionais consideraram incorreta a abordagem que a PEB conferiu à relação bilateral. Nas palavras do governador Dória (2020a) foi "um erro estratégico tanto de diplomacia como de relação comercial" a opção de colocar o alinhamento com os EUA como potencialmente excludente à cooperação com a China.

\footnotetext{
${ }^{8}$ Destaca-se que em março de 2020 foi celebrado entre Brasil e EUA um acordo de cooperação militar cujo aprofundamento foi sinalizado como possibilidade pelo governo Trump apenas se o país limitasse a participação da empresa chinesa Huawei nas redes de $5 \mathrm{G}$.
} 
Também o Consórcio Nordeste já expressou descontentamento com a política que o governo Bolsonaro tem direcionado à China (ARAÚJO; SILVA, 2020). Mesmo havendo setores do governo federal que incentivam maior pragmatismo nas relações bilaterais - a vicepresidência da república, o Ministério de Agricultura, Pecuária e Abastecimento (MAPA) e o Ministério da Economia ( $\mathrm{ME}$ ), que têm ligação com os setores mineral, do agronegócio e de energia, para os quais a China é importante mercado - "a discrepância nas declarações e atitudes" do governo federal e da família Bolsonaro "preocupa os chineses", fato que tem feito com que não só governadores brasileiros busquem diretamente a China, mas que também autoridades chinesas passem "a apostar em relações mais profundas com os governos estaduais no Brasil” (SANTORO, 2019, p.1).

\section{Efeitos da pandemia sobre a paradiplomacia e o acirramento da competição política}

Com o advento da pandemia de COVID-19, a PEB de Bolsonaro passou a aplicar todo o seu estoque de ideologia de ultra-direita e negacionismo científico à gestão nacional e externa do tema em relação à crise sanitária e às relações com a China (AZZI et al., 2020). Nesse sentido, os descontentamentos de governos subnacionais com a atuação internacional do governo federal foram amplificados pela chegada da pandemia. Tem-se apontado que a ausência de coordenação central por parte do governo federal de medidas para lidar com a COVID-19 é um dos principais motivos para explicar o desempenho ruim do país perante esse cenário. Abrucio et al (2020, p.670) argumentam que o combate a pandemia é um problema que "exige ainda mais coordenação intergovernamental que políticas corriqueiras", contudo o que imperou foi a "lógica de reduzir a coordenação federal", o que contribuiu para que ficasse sob responsabilidade dos governos subnacionais as decisões e implementações necessárias ao combate à pandemia.

A falta de coordenação federal gerou não só (i) dificuldades para que os entes federados pudessem acessar insumos, materiais e equipamentos no exterior para combater a pandemia, como (ii) criou embaraços para que implementassem políticas de isolamento 
visando diminuir o contágio do vírus. No que se refere ao primeiro ponto, Moreira (2020) destacou que a falta de coordenação deixou desamparados agentes públicos e privados, que sem grande experiência com importações, tiveram muitas dificuldades para acessar bens médicos no mercado internacional. Apontou-se ainda que a falta centralização levou a esforços concorrentes entre os entes federados e a própria União para compra de uma série de itens (VELASCO, 2020) ${ }^{9}$.

No que se refere ao segundo ponto, em relação a países da região, com destaque para os que compõem o Mercosul, o Brasil atrasou medidas de controle das fronteiras para barrar o vírus e, devido a posição do presidente de minimizar a gravidade da doença e propor para ela soluções já descartadas pela ciência ${ }^{10}$, as medidas de isolamento social acabaram sendo lideradas pelos governadores, o que reforçou um embate entre entes subnacionais e União, intensificando o conflito federativo. De acordo com Abrucio et al (2020, p. 671) "a ação dos estados aumentou o tom de confronto no discurso do presidente, que disse 'tem certos governadores que estão tomando medidas extremas, que não competem a eles'"', sendo que "Como reação, os governadores criticaram fortemente a postura centralizadora e sem diálogo do governo federal em documentos assinados quase unanimemente".

As medidas de isolamento social, assim, foram decididas e implementadas de forma local no Brasil, o que, segundo estudo apontado por Benites (2020), aumentou a velocidade de transmissão da COVID-19 entre a população. Não obstante, o governo federal tentou colocar embaraço as medidas de isolamento dos entes federados, que só não foram oficialmente revertidas porque o Supremo Tribunal Federal (STF) desautorizou o presidente da república (ABRUCIO et al., 2020), garantindo a autonomia de estados e municípios para decidir e atuar no contexto da pandemia sem ingerência da União (OLIVEIRA et al., 2020).

\footnotetext{
${ }^{9}$ Sobre esse aspecto, destaca-se como exemplo, segundo Alvarenga et al (2020), a concorrência da União com o Estado do Maranhão para a compra de respiradores. Tal competição levou a União a atravessar uma compra de respiradores do governo estadual. Para mais, ver Alvarenga et al (2020).

${ }^{10}$ Destaca-se que o presidente promoveu como remédios para a doença a invermectina e a hidroxicloroquina, já descartados como solução por cientistas, bem como questionou o isolamento social e o uso de máscaras como preventivos ao contágio, sendo que a comunidade científica tem apontado que tais aspectos são essenciais para o controle da transmissão da COVID-19.
} 
Foi diante desse horizonte de incertezas, que os entes federados se voltaram diretamente ao exterior para buscar meios que possibilitassem fortalecer o combate à pandemia. Nesse cenário, a China foi um dos países mais procurados pelos governos subnacionais pelo fato de ter mais experiência em lidar com a COVID-19, ser uma das maiores produtoras mundiais de equipamentos, insumos e outros materiais médicos necessários para combater a doença, e ter desenvolvido orientação diplomática - a diplomacia das máscaras voltada para a cooperação durante a pandemia. Governadores do Consórcio Nordeste, São Paulo, Rio de Janeiro, Distrito Federal e Pará, dentre outros, buscaram diretamente interlocução com a embaixada chinesa. Associações de Municípios, da qual foi exemplo a Associação dos Municípios da Zona de Produção (AMZOP), a maior entidade municipalista do Rio Grande do Sul, também pediram apoio direto à China para acessar materiais médicos, insumos e medicamentos (AMZOP, 2020). No flanco político, pela primeira vez as associações nacionais de municípios tomaram posição frontal contra o governo federal, pedindo a substituição de ministros. A Confederação Nacional de Municípios (CNM) pediu a saída do então Ministro da Saúde (Pazzuelo). Já a Frente Nacional de Prefeitos (FNP), pediu a saída do então Ministro das Relações Exteriores, Ernesto Araújo, "para recuperar a imagem do país no exterior" (VALOR, 2021).

Já no que se refere à busca da vacina, além de SP ter realizado acordo com a Sinovac, em 2020 o Estado do Paraná buscou concretizar uma parceria para teste e posterior compra e produção da vacina Sputnik V (da Rússia) no Brasil que, contudo, foi frustrado (o laboratório privado União Química que acabou por concluir um acordo com a Sputnik V). Outros estados da federação, entretanto, também passaram a realizar negociações próprias, principalmente após a aprovação do Projeto de Lei 534/21, em março de 2021, que autorizou estados, municípios e o setor privado a comprarem vacinas contra a Covid-19. Destaca-se a compra, em março de 2021, de 37 milhões de doses da Sputnik V pelo Consórcio Nordeste, e no caso de municípios, a formação de consórcios, como o organizado pela Frente Nacional de Prefeitos (FNP), para negociação e compra de vacinas. 
Enquanto isso, o governo federal se moveu lentamente. Até o final de 2020, além de ter aderido à cota mínima do Covax Facility ${ }^{11}$, havia concretizado apenas uma parceria para a compra e produção de vacina, a do consórcio da Universidade de Oxford com o laboratório Astrazeneca. Em dezembro de tal ano, quando a imunização já havia começado em vários países do mundo, inclusive em alguns da América do Sul, a incerteza quanto à vacinação nacional levou o STF a obrigar o governo federal a estabelecer um plano de imunização. Apenas em janeiro de 2021 o Ministério da Saúde (MS), então comandado pelo general Eduardo Pazuello, confirmou a compra da CoronaVac. O montante de vacinas contratadas até aquele momento, contudo, sendo 100 milhões de doses da Astrazeneca/ Fiocruz, 46 milhões da Sinovac/ Butantan e 42,4 milhões por meio da Covax Facility, considerando que todos os imunizantes precisariam de duas doses, eram insuficientes para o país, motivo pelo qual, após a aprovação do mencionado projeto de lei 534/21, estados e municípios buscaram se organizar para negociar imunizantes.

Apenas em fevereiro de 2021, o MS anunciou a compra de outro imunizante, a Covaxin, do laboratório indiano Bharat Biotech (20 milhões de doses), que, contudo, não obteve aprovação da ANVISA para uso no país ${ }^{12}$. Em março de 2021, após ter ignorado inúmeras propostas anteriores realizadas pela Pfizer, desde agosto de 2020, o MS contratou a compra de 100 milhões de doses do imunizante do laboratório, e de 38 milhões da Janssen, da Johnson \& Johnson. Em maio de 2021, adquiriu-se mais 100 milhões de doses da Pfizer, o que fez com que o montante de imunizantes contratados finalmente ultrapassasse o volume necessário para a vacinação em massa. Contudo, o atraso para as compras fez com que a maior parte dos imunizantes só possam ser entregues a partir do segundo semestre de 2021. O gerenciamento da pandemia pelo governo federal, em destaque o atraso para a compra de vacinas, motivou

\footnotetext{
${ }^{11} \mathrm{O}$ Covax Facility é um programa que existe dentro do projeto ACT Accelerator. O ACT é formado por um consórcio global de países, empresas e entidades, incluindo a OMS, visando a produção de vacina, medicamentos e diagnósticos contra o novo coronavírus. O Brasil integrou tal programa por pressão do legislativo e de forma tardia (AGÊNCIA BRASIL, 2020), optando na adesão ao Covax Facility, no qual os países poderiam reservar doses de vacinas, apenas pela cobertura mínima, de $10 \%$ da população, enquanto poderia ter chegado até $50 \%$.

${ }^{12}$ No momento em que finalizamos este texto, em julho de 2021, o contrato com a Covaxin encontra-se suspenso por suspeita de corrupção no Ministério da Saúde, apontada pela CPI da COVID-19.
} 
a instalação de uma Comissão Parlamentar de Inquérito (CPI) no Senado Federal, a CPI da COVID-19, instalada em 27 de abril de 2021.

A atuação diplomática do país também foi ineficiente perante a pandemia. Da perspectiva do então chanceler Araújo (2020), o vírus foi visto como uma "histeria biopolítica" ("covidismo") que facilitaria o globalismo (na visão dele, a atual fase do comunismo). Tal entendimento da pandemia fez com que, em seguimento a posição do próprio presidente, a diplomacia assumisse uma postura negacionista perante a doença (ALVARENGA et al., 2020). Refletindo a visão crítica as Ols e ao multilateralismo (vistos como instrumentos do globalismo) assumida pelo Itamaraty, a diplomacia brasileira censurou a Organização Mundial da Saúde (OMS), a qual ameaçou abandonar em junho de 2020 (logo após Trump ter declarado a retirada dos EUA da organização), bem como, contrariando posições históricas, alinhou-se aos países desenvolvidos no que diz respeito às discussões sobre a possibilidade de licença compulsória de patentes de vacinas da COVID-19.

Assim, ao tratar a pandemia como "histeria" e nova oportunidade para reafirmar o alinhamento com o governo $\operatorname{Trump}^{13}$, a diplomacia diferenciou-se da paradiplomacia, que buscou agir pragmaticamente (tal qual o Itamaraty sempre agiu nas últimas décadas) junto a outros países, a partir da ação de governos federados que, no geral, esforçaram-se mais para seguir e promover as recomendações da OMS e da comunidade científica. Destaca-se ainda que nesse cenário de disputa houve a politização da pandemia, que é "a utilização política da ciência para fins pessoais e/ou eleitorais" (AMARAL, 2020), potencializada pela disputa política entre os governadores e o presidente.

As eleições majoritárias de 2022 estão no radar dos governadores, que devem usar medidas de combate à pandemia por eles promovidas, bem como as atividades paradiplomáticas que têm desenvolvido para impulsionar suas chances de vitória (RODRIGUES, 2019; KHALIL, 2020) ${ }^{14}$. Com efeito, vários governos subnacionais vêm

\footnotetext{
${ }^{13} \mathrm{Tal}$ alinhamento evidenciou-se no apoio que a diplomacia brasileira deu a proposição estadunidense de investigar a origem da pandemia na China, algo a qual os chineses se opuseram; na adoção de discurso crítico ao papel da OMS no combate a COVID-19, além da já citada votação na qual o Brasil preferiu seguir a posição de não permitir a licença compulsória para as vacinas contra o novo coronavírus.

${ }^{14}$ Dados do Instituto DataFolha têm mostrado que, no geral, a avaliação da população sobre o desempenho dos governadores perante a pandemia é maior do que de Bolsonaro $(G 1,2021)$. Por exemplo, segundo o DataFolha,
} 
desenvolvendo relações externas que marcam posições diferentes daquelas defendidas pelo governo federal, algo que tem sido frequentemente apontado pela literatura como motivadoras de conflitos entre governos centrais e subnacionais. De fato, um dos motivos para explicar a nova paradiplomacia, exemplificada na contraposição existente entre SP e governo federal sobre a CoronaVac, é a disputa política entre Dória e Bolsonaro, como apontaremos na próxima seção.

\section{A PARADIPLOMACIA DE SP E A VACINA CORONAVAC}

Em junho de 2020 foi divulgada pelo governo de SP a realização de uma parceria entre - Instituto Butantan, e a farmacêutica de origem chinesa Sinovac Life Science, do grupo Sinovac Biotech, visando a realização de testes clínicos e a produção de uma vacina contra a COVID-19. Desde então, as questões referentes a essa vacina têm contraposto SP e governo federal. Tal caso de desacordo é um dos principais exemplos de que na gestão Bolsonaro há choque entre o governo central e as atividades paradiplomáticas dos governos subnacionais.

\section{Atuação internacional de SP e os choques com a gestão Bolsonaro}

Como afirma Rodrigues (2019, p. 1), a paradiplomacia tem sido bem estruturada em SP, em especial nos últimos dez anos, "visando a atração de investimentos, negócios e comércio". Lembra-se que o Estado tem histórico de inserção internacional, SP criou pela primeira vez sua Secretaria de Relações Internacionais (SRI) em 1991, e embora tal secretaria tenha sido extinta em 1995, o Estado continuou exercendo atividades internacionais, sendo que em 2005 reconstituiu-se novamente uma unidade de assessoramento voltada às relações internacionais dentro do governo. Durante a gestão de Geraldo Alckmin (2011-2014, 20152018), a Assessoria Especial para Assuntos Internacionais criou um arquivo diplomático de SP e lançou em 2012 o primeiro plano de um estado brasileiro para as RIs - "São Paulo no Mundo:

entre março de 2020 e maio de 2021, a avaliação do desempenho do presidente perante a pandemia caiu de $35 \%$ para $21 \%$ na categoria ótimo/bom e subiu de $26 \%$ para $51 \%$ de ruim/péssimo. Já no caso dos governadores, embora também tenha caído a avaliação na categórica ótimo/bom (de 54\% para 35\% entre março de 2020 e maio de 2021), e subido a avaliação ruim/péssimo (de 16\% para 29\%), o desempenho continua sendo melhor avaliado que o presidente $(G 1,2021)$. 
Plano de Relações Internacionais - 2011-2014", com a presença do então chanceler Antonio Patriota (TAVARES, 2012; 2014). A partir de 2019, com a gestão Dória, tal estrutura foi novamente elevada à Secretaria de Estado.

Como afirma Medeiros (2010, p. 175, tradução nossa), de forma geral, as atividades paradiplomáticas de SP tiveram ao longo do tempo elevado grau de convergência com a política externa central, devido ao fato de o Estado ter força o suficiente para influenciar "a estrutura institucional que gera output na política externa nacional”. A partir do governo Bolsonaro, entretanto, essa percepção de convergência com a diplomacia se esvaiu.

Do lado ambiental, diferenciando-se da orientação climática-negacionista da diplomacia oficial, o governo Dória lançou em 2019 o “Acordo Ambiental São Paulo" para incentivar ações de sustentabilidade e reduzir a emissão de GEE, no qual se fez questão de apontar as diferenças com as políticas do governo federal. Segundo Dória, "São Paulo respeita o Acordo de Paris [...] Temos uma boa relação com as instituições que defendem o meio ambiente" (GOVERNO DO ESTADO DE SÃO PAULO, 2019a, p. 1). No mesmo sentido, o secretário de relações internacionais de SP, Júlio Serson, destacou que o governo "tem trabalhado em múltiplas ações com foco nessa conciliação urgente entre meio ambiente e desenvolvimento econômico", o que contrastaria com o governo federal (GOVERNO DO ESTADO DE SÃO PAULO, 2019a, p. 1).

É na política com a China, contudo, que os choques com o governo federal têm ocorrido com mais intensidade. Destaca-se que SP realizou, em 2019, a Missão China, cujo objetivo foi atrair investimentos, em especial em infraestrutura ${ }^{15}$, "promover os produtos de São Paulo e ampliar as relações comerciais do Estado com o mercado chinês" (GOVERNO DO ESTADO DE SÃO PAULO, 2019b, p.1). Durante tal viagem foi inaugurado o escritório de SP em Xangai pago pelos próprios chineses visando incentivar as relações paradiplomáticas. Segundo Dória (2019, p. 1), o escritório estaria "voltado para a promoção do comércio e de investimentos e o intercâmbio de tecnologia, infraestrutura, agronegócio, saúde, energia, educação e turismo".

\footnotetext{
${ }^{15}$ A Missão apresentou 21 projetos disponíveis para investimentos chineses (16 de concessões e 5 de Parcerias Público Privadas), sendo 52\% deles na área de transportes (GOVERNO DO ESTADO DE SÃO PAULO, 2019b).
} 
Destaca-se que a China tem sido vista por SP como um país estratégico para aproximação. Como o próprio governador destacou, há relevante presença de chineses no estado ( $90 \%$ dos 200 mil chineses que residem no Brasil estão em SP), que é também um dos principais parceiros econômicos da China dentro do país: “O Estado de São Paulo compra 38\% de todos os produtos manufaturados da China que chegam ao Brasil. A China é o segundo destino das exportações de São Paulo" (DÓRIA, 2019, p. 1) ${ }^{16}$.

Enfatiza-se ainda que SP é o ente federado que mais recebe investimentos chineses, sendo que em um cenário de incertezas geradas pelas orientações do governo federal, o Estado tem atuado para se colocar como "porto seguro" para a entrada de investimentos da China no país, segundo Dória (2019, p.1), “o entendimento" é que "São Paulo tem o que [os chineses] desejam: bons projetos, com segurança jurídica". Nessa linha, segundo Serson, SP tem uma "relação de confiança e de muita expectativa" com os chineses, "com quem queremos fortalecer e ampliar relações econômicas, mas também institucionais, em múltiplos setores" (GOVERNO DO ESTADO DE SÃO PAULO, 2019c, p. 1), o que contrasta com a orientação dada a diplomacia central, de restringir as relações com a China, como foi sugerido pelo então chanceler (ARAÚJO, 2019).

Com a evolução das tensões nas interações Brasil-China ao longo da gestão Bolsonaro, SP agiu no sentido de marcar as diferenças de posicionamento entre o governo estadual e federal. Quando Eduardo Bolsonaro insinuou em rede social, em março de 2020, que a culpa da pandemia de COVID-19 era da China, Dória (2020b) classificou de "lamentável e irresponsável" as declarações do deputado, afirmando que ele "envergonha os brasileiros".

A SRI, por sua vez, tem conduzido a paradiplomacia em direção à China destacando pontos de convergência entre os países, em orientação diversa da diplomacia central do então ministro Araújo, na qual se destacou constantemente contraposições entre Brasília e Beijing. Conforme afirma Serson, é possível "pensar diferente e ainda sim estabelecer parcerias", denotando-se pragmatismo nas relações externas de SP, algo que segundo o secretário é reconhecido pelas contrapartes chinesas: "As autoridades chinesas respeitam e entendem

${ }^{16}$ Os dados apresentados pelo governador tiveram como base o ano de 2018. 
que em São Paulo há uma linha diferente da adotada pelo governo federal" (SERSON, 2020, p. 1). Segundo o diplomata que é Secretário-Executivo na SRI, Affonso Massot, é possível perceber que a paradiplomacia de SP se guia por aspectos que caracterizaram tradicionalmente a PEB, mas que perderam espaço no governo Bolsonaro:

[...] se orienta por princípios como o universalismo de suas relações internacionais, a defesa dos direitos humanos, da liberdade econômica e da preservação ambiental, buscando a atração de cooperação e de investimentos internacionais, tendo como objetivos prioritários os interesses de São Paulo e o crescente bem-estar da população paulista. ${ }^{17}$

Ressalta-se que, diferentemente do Itamaraty na gestão Araújo, o governo estadual não tratou EUA e China como parceiros excludentes nas suas relações externas, uma vez que SP avançou paralelamente a interlocução direta com os dois países a partir do entendimento de que "o momento de disputa comercial entre EUA e China abre oportunidades para o Brasil”, contudo cabe ao país “buscar e concretizar esses negócios” (DÓRIA, 2019, p. 1).

\section{O acordo para a vacina CoronaVac}

Em junho de 2020 foi estabelecido entre o Instituto Butantan, instituição ligada a SP, e a Sinovac Life Science o "Acordo de Colaboração de Desenvolvimento Clínico", a partir do qual se viabilizou a realização de testes clínicos da Fase III, para a vacina CoronaVac, com 13 mil voluntários - profissionais da saúde em contato direto com pacientes da COVID-19 - de diferentes Estados da federação. O custo estimado para testagem no país, arcado por SP, foi de R\$ 85 milhões (PINHONI; FIGUEIREDO, 2020). Como foi afirmado pela SRI, por intermédio de seu Secretário-Executivo, Affonso Massot ${ }^{18}$, as negociações entre o Instituto Butantan e a Sinovac foram feitas de maneira direta, sem nenhuma participação, ainda que indireta, do MRE.

Um aspecto que facilitou o acordo da Sinovac com o Butantan foi o fato de o Instituto já ter iniciado uma trajetória de internacionalização de suas atividades anteriormente ao momento da pandemia, no qual a aproximação entre SP e China promovida pela gestão Dória foi importante. Assim, a iniciativa para a vacina "pode ser classificada como um

\footnotetext{
${ }^{17}$ Entrevista do Embaixador Affonso Massot concedida aos autores, em 2021.

18 Idem.
} 
desdobramento da cooperação bilateral SP-China, que inclui empresas chinesas, no campo da ciência e da tecnologia", conforme afirmou Massot ${ }^{19}$.

Como assinala Cruz (2020, p.1), a diretoria do Instituto já vinha planejando a inserção da instituição no mercado internacional de vacinas: "a meta para 2020 era incluir o instituto entre os três maiores produtores do mundo". Em 2019, tendo como objetivo ampliar sua inserção, fechou algumas parcerias incluindo empresas chinesas - caso da Bravovax - visando o licenciamento de dados da vacina de rotavírus humano (MOTTA, 2020).

Para o acordo com a Sinovac, Dimas Covas (2020, p.1), diretor do Instituto, afirmou que foi essencial a participação prévia do Butantan em organismos internacionais que discutiam o tema da pandemia, com destaque para o Developing Countries Vaccine Manufacturers Network (DVCMN), no qual a instituição ocupou a vice-presidência até 2019. Foi por meio de contatos estabelecidos por meio desse grupo que o Instituto começou um processo de apuração para compreender "quem tinha projeto de vacina, em que pé estava, para onde caminhava" as tentativas de diversos produtores, logo após o início da pandemia (CRUZ, 2020, p.1). Como resultado, foram fechados alguns acordos confidenciais para troca de informações com vários possíveis parceiros (CRUZ, 2020).

Entretanto, como assinala Cruz (2020), Butantan e Sinovac já se conheciam. Na Missão China realizada em 2019 por SP, da qual o Instituto participou, visitas tinham sido realizadas a várias farmacêuticas chinesas, dentre elas a Sinovac. Logo após, a empresa retribuiu a visita ao Butantan. Com o início da pandemia e ciente do interesse do Butantan, segundo Cruz (2020, p.1), "a empresa avisou que tinha uma vacina feita para outra epidemia, a do Sars-CoV1, que já estava em estudos pré-clínicos para ser adaptada para o Sars-CoV-2. Covas também fechou com eles um acordo para troca de informações".

Apesar do Instituto ter feito contato com outras empresas, a opção foi pela parceria com a SinoVac. Segundo o Butantan (apud MOTTA, 2020), naquele momento, dentre as plataformas tecnológicas compatíveis com a do Instituto, a SinoVac estava em estágio avançado. Já Cruz (2020) argumenta que seriam quatro principais motivos para a escolha da

\footnotetext{
${ }^{19}$ Idem.
} 
Sinovac: (i) o fato de serem duas instituições parecidas em tamanho e portfólio de vacinas, o que traria mais equidade às negociações; (ii) o Butantan já possuía relativo domínio sobre a tecnologia utilizada na vacina em questão, uma vez que é a mesma empregada no imunizante da raiva humana e da dengue; (iii) a empresa chinesa tinha muito interesse em realizar acordo com contraparte de um país que ainda estivesse sendo significativamente afetado pela pandemia, de forma que fosse possível realizar os testes clínicos, e; (iv) interessava à Sinovac que o parceiro já tivesse previamente inserção internacional, o que era o caso do Butantan.

A possibilidade de ocorrência de transferência tecnológica também foi aspecto importante do acordo. Embora esteja claro no acordo inicial que a "SINOVAC detém os direitos de propriedade intelectual" (JUNQUEIRA, 2020), desde o início se previu a realização de contratos aditivos visando a transferência de tecnologia da Sinovac para o Butantan (XINHUA, 2020). Tal fato começou a se concretizar em setembro de 2020, quando Butantan e Sinovac celebraram um contrato que não só previa "o fornecimento de 46 milhões de doses da vacina Coronavac", sendo 6 milhões importadas da China e 40 milhões produzidas pelo Butantan, mas igualmente "a transferência de tecnologia da vacina, que deverá ser produzida integralmente no próprio Instituto Butantan a partir do próximo ano" (INSTITUTO BUTANTAN, 2020).

Embora especialistas duvidem que a totalidade da produção - formulação do produto, envase e rotulagem - possa ser feita pelo Instituto em prazo tão curto (FOLHAPRESS, 2020) ${ }^{20}$, no que se refere às duas últimas etapas, já foi possível iniciar a produção em 2020 (GOVERNO DO ESTADO DE SÃO PAULO, 2020). Ressalta-se ainda que em novembro de 2020 iniciou-se a reforma de uma das estruturas fabris envolvidas na produção da CoronaVac, o que permitirá a produção de até 100 milhões de doses por ano (MONTEIRO, 2020).

\footnotetext{
${ }^{20}$ Especialistas apontaram que mesmo a vacina sendo feita com uma tecnologia que o Instituto já conhece, a partir de vírus inativado, a produção exigirá instalações especiais para a realização das culturas nas células de vírus que serão utilizadas no imunizante. Apontou-se ainda que é comum que os laboratórios que detêm a patente, no caso a Sinovac, atrasem a transferência de tecnologia para poderem se apropriar do mercado inicial (FOLHAPRESS, 2020).
} 


\section{Os conflitos em torno da vacina}

No conflito em torno da CoronaVac, o primeiro fator explicativo é o papel que as diferentes esferas da federação atribuíam à China. O governo de SP conferiu a ela papel de relevo nas suas relações externas, com reconhecimento da importância, em especial econômica do país, e o desejo de aprofundar as relações sino-paulistas de forma pragmática. No caso do acordo com a Sinovac, como afirmou Dimas Covas (2020, p.1), a China é hoje, em vários aspectos, "uma potência científica maior do que o Estados Unidos", não se justificando assim preconceito contra a vacina pelo fato de ela ter como origem um laboratório chinês.

Em contrapartida, a diplomacia de Araújo questionou o papel da China para o Brasil, e buscou com o governo Trump um alinhamento da PEB excludente à cooperação com a China. No que se refere à CoronaVac, a visão de China no governo federal não foi compatível com a promoção de uma vacina de origem chinesa como algo que ajudasse a mitigar o problema da pandemia no país. Tanto Araújo, como Bolsonaro e seus filhos, adotaram o discurso trumpista de que a China era culpada pelo novo coronavírus.

Várias declarações do presidente demonstraram que parte dos problemas que o governo federal criou com a CoronaVac se deveu ao fato de ela ter origem chinesa. A título de exemplo, em julho de 2020, em live em uma rede social, Bolsonaro (2020a) afirmou: "se fala muito da vacina da COVID-19. Nós entramos naquele consórcio lá de Oxford. Pelo que tudo indica, vai dar certo e 100 milhões de unidades chegarão para nós. Não é daquele outro país não, tá ok, pessoal? É da Oxford aí". No contexto da publicação, restou claro que o "outro país" do qual o presidente não gostaria de obter vacinas era a China.

Já em outubro, após a divulgação de que o Ministério da Saúde teria assinado um protocolo de intenções com o Instituto Butantan para compra de 46 milhões de doses da CoronaVac, o presidente fez o então ministro Pazuello voltar atrás da decisão, desautorizando-o publicamente de celebrar o acordo. Pelas declarações que se seguiram, foi perceptível que Bolsonaro estava discriminando a vacina por sua origem chinesa, conforme confirmou: "Da China não compraremos [a vacina]. Não acredito que ela transmita segurança 
para a população pela sua origem. Temos certeza que outras vacinas que estão em estudo poderão ser comprovadas cientificamente" (BOLSONARO, 2020b).

A recusa do governo federal em comprar a vacina durante 2020 provocou incerteza nos governos subnacionais. Ressalta-se que é atribuição da União a compra de vacinas desde 1975, quando se criou o Programa Nacional de Imunização. Assim, a hesitação sobre as ações do governo federal com relação à vacina e a concorrência criada com SP após celebração do acordo com a Sinovac para fornecimento delas, também contribuíram, a par da discriminação à China, para o entendimento do conflito entre o ente federado e o governo federal. Tal concorrência foi calcada não só no fato de que (i) se tornou mais acirrado o conflito federativo durante a pandemia, mas igualmente (ii) na emergente disputa política entre o presidente Bolsonaro e o governador Dória.

No que se refere ao primeiro fator, especificamente no que diz respeito à vacina, além de criticar sua origem chinesa, Bolsonaro opôs-se à indicação de vários governadores, dentre eles Dória, de que a vacinação deveria ser colocada como obrigatória no país. Em reunião do G20, sediada pela Arábia Saudita, e realizada virtualmente em novembro de 2020, Bolsonaro fez a defesa da vacinação opcional, assumindo posição praticamente isolada na conferência sobre esse tema. Esse choque de orientações acabou por ser decidido em dezembro de 2020 pelo STF em favor dos estados, estabelecendo a obrigatoriedade da vacinação. Contudo, o presidente já havia feito várias declarações associando a obrigatoriedade da imunização e a possível ocorrência de efeitos adversos com a CoronaVac ${ }^{21}$.

No que diz respeito ao segundo fator, resta claro nas declarações do presidente que não se trata apenas de conflito federativo, uma vez que houve tanto por parte dele, como por parte de Dória, a tentativa de associar a CoronaVac - para o "bem", no caso do governador, ou para o "mal", no caso de Bolsonaro - à figura do mandatário estadual. As atividades paradiplomáticas do governo Dória e a iniciativa para o acordo com a Sinovac, em especial, não podem ser interpretadas meramente como atuação técnica. Segundo Khalil (2020, p.1)

\footnotetext{
${ }^{21}$ Em novembro de 2020, na ocasião da suspensão dos testes de tal vacina pela ANVISA, em sua página em uma rede social, o presidente afirmou: "Morte, invalidez, anomalia. Esta é a vacina que o Doria queria obrigar todos os paulistanos a tomá-la. O presidente disse que a vacina jamais poderia ser obrigatória" (BOLSONARO apud TEIXEIRA, 2020).
} 
sabe-se "que por detrás da questão sanitária, há muito mais. O palanque das eleições presidenciais de 2022 já está armado e a inserção internacional pode ser um importante cabo eleitoral"22.

Especialistas têm apontado que para concorrer com mais chances as eleições presidenciais de 2022, o governador paulista precisa se "nacionalizar" (AMORIM, 2020), algo que o imunizante da CoronaVac poderia ajudar, uma vez que por meio dele o governador se apresentaria como interlocutor nacional para um problema que o governo federal não ofereceu solução, em especial após a divulgação, em dezembro de 2020, do Plano Estadual de Imunização (PEI) de SP, que reforçou a politização da pandemia e colocou mais pressão sobre o governo federal e outros estados da federação para que apresentassem também alternativa à população. Aspecto importante do PEI - que foi divulgado em um momento em que nem governo federal, nem estaduais possuíam planos de vacinação -, que visou reforçar o perfil do governador como figura nacional, foi que Dória estabeleceu que qualquer brasileiro, fosse ou não de SP, poderia tomar a vacina, desde que enquadrado dentro dos grupos que estivessem sendo imunizados.

Após a divulgação do PEI, tanto a disputa política, como os conflitos federativos acirraram-se mais. Em discussão entre o governador de SP e Pazuello, em dezembro de 2020, o então ministro questionou o fato de Dória associar a vacina a SP: "Não sei por que o senhor diz tanto que ela é de São Paulo" (PAZUELLO apud MURAKAWA, 2020). Ao perceber a importância que a vacina tomou dentro do debate político e social brasileiro, o próprio presidente Bolsonaro (apud DIAS 2021), contradizendo suas ações e falas ao longo de 2020, afirmou de forma mentirosa: "nunca fui contra a vacina, sempre disse 'passou pela Anvisa, compra'. Tanto é que a CoronaVac passou pela tangente", em uma das tentativas de colocar o governo federal como protagonista na situação. Embora, saiba-se que assuntos de política externa não são frequentemente mobilizados nas eleições, dado o relativo desinteresse do

22 Em pesquisa DataFolha de janeiro de 2021, sobre quem estava fazendo mais pelo Brasil no combate a pandemia, 46\% apontaram que era Dória, enquanto 28\% Bolsonaro (DATAFOLHA, 2021). Embora haja indefinição sobre se Dória irá se candidatar para o pleito de 2022, em pesquisa DataFolha, de julho de 2021, para intenção de voto para presidente, o governador apareceu em 4 ㅇ lugar, com $5 \%$ dos votos, atrás de Lula (46\%), Bolsonaro (25\%) e Ciro (8\%). Na simulação de 2 o turno, contudo, Dória, com 46\%, venceria Bolsonaro, com 35\% (GIELOW, 2021). 
público pelo tema, o tratamento dado pelos governos a pandemia e a questão da vacinação, como mostrou a derrota de Trump nos EUA, criticado pela postura perante a COVID-19, e a vitória do Partido Conservador no Reino Unido em 2021 - do qual faz parte o primeiroministro britânico, Boris Johnson, que tem sido elogiado pelo rápido avanço da vacinação -, esse tema externo deve ser uma das variáveis a impactar as eleições.

Em 29 de março de 2021, o ministro Ernesto Araújo pediu demissão, dias depois de uma crise desencadeada com congressistas, após confrontá-las em audiência pública do Congresso Nacional. Sua substituição pelo Embaixador Carlos Alberto França - diplomata discreto e pouco conhecido, sem vínculo com o núcleo duro do presidente - foi celebrada por governistas moderados e pela oposição como derrota do grupo ideológico do governo e oportunidade para retomar as relações com a China. Desde então, o MRE deixou de ser uma fonte de ataques à China, mas isso não tem impedido que o próprio Bolsonaro continue criticando e confrontando a diplomacia chinesa com insinuações e declarações discriminatórias àquele país e à vacina Coronavac ${ }^{23}$.

\section{CONSIDERAÇÕES FINAIS}

Uma das variações importantes da cooperação internacional contemporânea é a que se realiza de forma descentralizada, por meio da paradiplomacia e, no âmbito mais recente desse fenômeno, as ações internacionais de governos subnacionais impulsionadas pela pandemia de COVID-19. Neste artigo, demonstramos que durante o governo Bolsonaro, mudanças na Política Externa Brasileira (PEB), bem como o cenário de pandemia da COVID19, foram motivadores de atividades paradiplomáticas de governadores estaduais em conflito com a União em temas como Meio Ambiente e Saúde.

A partir da análise da paradiplomacia do Estado de São Paulo (SP), especificamente no que se refere ao acordo com a Sinovac, avaliou-se um conjunto de fatores que explicam o conflito entre União e governo estadual. Mostramos que mudanças na PEB direcionadas à

\footnotetext{
${ }^{23}$ A título de exemplo, cita-se a insinuação do presidente, em maio de 2021, de que a pandemia de COVID-19 podia ser parte de uma "guerra bacteriológica" que visaria beneficiar o país que "mais cresceu o seu PIB", claramente se referindo a China.
} 
China, a falta de coordenação do governo federal para articular medidas de combate a pandemia, considerando-se ainda o negacionismo do presidente, e disputas políticas são os principais fatores a explicar o conflito entre SP e governo federal. Assim, a paradiplomacia foi utilizada para exercer a autonomia federativa em cenário de crise sanitária, cabendo destacar que apesar de a União ter decidido, afinal, comprar a CoronaVac no início de 2021, não se descaracterizou o conflito em torno dessa questão. Agregue-se que, a par do argumento central deste artigo de que a paradiplomacia estadual, em particular de SP, atuou em chave de conflito com a União, pode-se também interpretar que as ações internacionais dos governadores se mantiveram alinhadas com a diplomacia tradicional do Itamaraty, enquanto órgão de Estado, diante de um governo de extrema-direita que privou o MRE de seu processo decisório racional.

O debate sobre o impacto que as ações descentralizadas no curso da pandemia terão na dinâmica federativa doméstica e internacional no Brasil, nos médio e longo prazos, ganha particular interesse no pós-pandemia. Tendo em vista que a política externa tem sido historicamente uma área marcada pelo insulamento burocrático do Itamaraty, o fato de que nos últimos anos a PEB tenha se tornado mais aberta, multidimensional e capilarizada por novos atores governamentais e não governamentais (MILANI et al, 2012), ganha um novo momentum de legitimidade local-internacional, na medida em que coloca em destaque um vetor de atuação dos governos subnacionais que se desloca, de maneira coletiva, de sua histórica atuação convergente com a União.

Ressalta-se, por fim, que o emergente conflito entre governos subnacionais e federal nas suas iniciativas externas no contexto da pandemia de COVID-19 abrem vasto campo de pesquisa de uma vertente da paradiplomacia no Brasil, em especial no que se refere às relações e à cooperação internacional com a China.

\section{REFERÊNCIAS}

ABRUCIO, Fernando Luiz; GRIN, Eduardo José; FRANZESE, Cibele; SEGATTO, Catarina Ianni; COUTO, Claúdio G. Combate à COVID-19 sob o federalismo bolsonarista: um caso de 
descoordenação intergovernamental. In: Revista De Administração Pública. Rio de Janeiro 54(4):663-677, jul. - ago. 2020. Disponível em: < https://www.scielo.br/pdf/rap/v54n4/19823134-rap-54-04-663.pdf> Acessado em 06 de janeiro de 2021.

AGÊNCIA BRASIL. Brasil entra em consórcio global para produção de vacina contra a Covid19. 03 jun 2020. Disponível em <https://www.cnnbrasil.com.br/saude/2020/06/03/brasilentra-em-consorcio-global-para-producao-de-vacina-contra-a-covid-19> Acesso em 20 jun 2020.

ALVARENGA, Alexandre Andrade; ROCHA, Erika M. S; FILIPPON, Jonathan; ANDRADE, Maria Angélica $C$. Desafios do Estado brasileiro frente à pandemia pela Covid-19: o caso da paradiplomacia maranhense. 2020. Disponível em

$<$ https://preprints.scielo.org/index.php/scielo/preprint/download/738/987/1030> Acessado em 06 de janeiro de 2021.

AMARAL, Alberto. Politização da pandemia serve a fins eleitorais, mas não à ciência. [Entrevista concedida a] Simone Lemos. In: Rádio USP, 06/10/2020. Disponível em: $<$ https://jornal.usp.br/radio-usp/politizacao-da-pandemia-serve-a-fins-eleitorais-mas-nao-aciencia/> Acessado em 06 de janeiro de 2021.

AMORIM, Silvia. De olho em 2022, João Doria tem entre seus desafios aplacar taxa de rejeição. In: O Globo, 06/12/2020. Disponível em: < https://oglobo.globo.com/brasil/deolho-em-2022-joao-doria-tem-entre-seus-desafios-aplacar-taxa-de-rejeicao-24783681> Acessado em 06 de janeiro de 2021.

AMZOP - Associação dos Municípios da Zona de Produção. Ofício no 037/2020. 23 de março de 2020. Disponível em < https://liberatosalzano.rs.gov.br/noticia/visualizar/id/1272/?coronavirus-prefeitos-daregiao-sul-pedem-ajuda-a-china.html> Acessado em 24 de maio de 2021.

ARAÚJO, Ian Filipe Costa; SILVA, Jaqueline Victória Santana. Paradiplomacia e a atuação internacional do Consórcio Nordeste durante a pandemia de COVID-19. 2020. Disponível em <https://integri.com.br/trabalhos-apresentados/paradiplomacia-e-a-atuacaointernacional-do-consorcio-nordeste-durante-a-pandemia-de-covid-19/> Acessado em 06 de janeiro de 2021.

ARAÚJO, Ernesto. Aula magna do ministro Ernesto Araújo aos novos diplomatas do Instituto Rio Branco. 11/03/2019. Disponível em < https://www.youtube.com/watch?v=0Qt1kCY7D0M> Acessado em 06 de janeiro de 2021.

ARAÚJO, Ernesto. Por um Reset Conservador-Liberal. 2020. Disponível em: < https://www.metapoliticabrasil.com/post/por-um-reset-conservador-liberal> Acessado em 06 de janeiro de 2021. 
AZZI, Diego A.; RODRIGUES, Gilberto M. A.; SOUSA, Ana. T. M. (Org.). A política externa de Bolsonaro na pandemia. São Bernardo do Campo: FES, 2020. Disponível em: http://library.fes.de/pdf-files/bueros/brasilien/17340.pdf

BENITES, Afonso. Quase 70\% dos municípios adotaram distanciamento social antes do primeiro caso de coronavírus. In: El País, 09/09/2020. Disponível em: < https://brasil.elpais.com/brasil/2020-09-09/quase-70-dos-municipios-adotaramdistanciamento-social-antes-do-primeiro-caso-de-coronavirus.html> Acessado em 06 de janeiro de 2021.

BOGÉA FILHO, Antenor. A Diplomacia Federativa. Brasília: Funag, 2001.

BOLSONARO, Jair. Íntegra da live de Jair Bolsonaro de 30/07/20. Ano: 2020a. Disponível em: < https://www.youtube.com/watch?v=XVTIKG2KLM8> Acessado em 06 de janeiro de 2021.

BOLSONARO, Jair. Confira a entrevista exclusiva com o presidente Jair Bolsonaro em Os Pingos nos Is. [Entrevista concedida a] Os Pingos nos Is. 21/10/2020. Ano: 2020b. Disponível em: < https://jovempan.com.br/programas/os-pingos-nos-is/exclusivo-bolsonaro-diz-quenao-tomara-vacina-chinesa.html> Acessado em 06 de janeiro de 2021.

BRASIL. ComexVis. 2020. Disponível em < http://comexstat.mdic.gov.br/pt/comex-vis> Acesso em 05 dez. 2020.

COSTA, Cássia M. S. Marques. Governos Subnacionais e Política Externa: o Caso da Agenda de Mudanças Climáticas. Dissertação (Mestrado em Relações Internacionais). Programa de Pós-Graduação em Relações Internacionais da Universidade de São Paulo (USP), São Paulo, 2013.

COSTA, Rui. Sem recursos de Brasília, governadores do Nordeste buscam parcerias na Europa. [Entrevista concedida a] RFI. In: RFI, 18/11/2019. Disponível em < https://www.rfi.fr/br/fran\%C3\%A7/20191120-sem-recursos-de-bras\%C3\%ADliagovernadores-do-nordeste-v\%C3\%A3o-\%C3\%A0-europa-em-busca-de-parcerias $>$ Acessado em 06 de janeiro de 2021.

COUTO, Carolina. Paradiplomacia e o caso do Fundo Amazônia, 20 de janeiro de 2020. Disponível em < https://medium.com/@Carolina Couto/paradiplomacia-e-o-caso-do-fundoamaz\%C3\%B4nia-75bdc6ebf017> Acessado em 24 de maio de 2021.

COVAS, Dimas. Com fé na ciência e na religião, Dimas Covas é o homem por trás da Coronavac no Brasil. [Entrevista concedida a] Angélica Santa Cruz. In: Estadão. 19/12/2020. Disponível em: < https://saude.estadao.com.br/noticias/geral,com-fe-na-ciencia-e-na- 
religiao-dimas-covas-e-o-homem-por-tras-da-coronavac,70003557479> Acessado em 06 de janeiro de 2021.

CRUZ, Angélica Santa. Com fé na ciência e na religião, Dimas Covas é o homem por trás da Coronavac no Brasil. In: Estadão. 19/12/2020. Disponível em: < https://saude.estadao.com.br/noticias/geral,com-fe-na-ciencia-e-na-religiao-dimas-covas-eo-homem-por-tras-da-coronavac,70003557479> Acessado em 06 de janeiro de 2021.

DATAFOLHA. Para 46\%, João Doria é quem está fazendo mais pelo país na pandemia. 27/01/2021. Disponível em <https://datafolha.folha.uol.com.br/opiniaopublica/2021/01/1989214-para-46-joao-doria-equem-esta-fazendo-mais-pelo-pais-na-pandemia.shtml> Acessado em 10 de julho de 2021.

DIAS, Roger. 'Nunca fui contra a vacina', diz Bolsonaro. É mentira. In: Estado de Minas, 09/02/2021. Disponível em < https://www.em.com.br/app/noticia/politica/2021/02/09/interna_politica,1236389/nuncafui-contra-a-vacina-diz-bolsonaro-e-mentira.shtml> Acessado em 24 de maio de 2021.

DÓRIA, João. Bolsonaro passa mensagem atentatória à vida dos brasileiros, diz Doria. [Entrevista concedida a] DW Brasil. In: DW Brasil, 10/06/2020. Ano: 2020a. Disponível em <https://www.dw.com/pt-br/bolsonaro-passa-mensagem-atentat\%C3\%B3ria-\%C3\%A0-vidados-brasileiros-diz-doria/a-53762110> Acessado em 06 de janeiro de 2021.

DÓRIA, João. Lamentável e irresponsável a declaração feita pelo filho do presidente, deputado @BolsonaroSP, sobre a China. 19 de Março de 2020, 8h57. Twitter: @jdoriajr. Ano: 2020b. Disponível em: <https://twitter.com/jdoriajr/status/1240608211310465027> Acessado em 06 de janeiro de 2021.

DÓRIA, João. São Paulo e China, uma história promissora. In: Estadão. 10/08/2019. Disponível em: < https://opiniao.estadao.com.br/noticias/espaco-aberto, sao-paulo-e-chinauma-historia-promissora,70002961814> Acessado em 06 de janeiro de 2021.

DUCHACEK, Ivo D. Perforated Sovereignties: Towards a Typology of New Actors in International Relations. In: MICHELMANN, Hans J.; SOLDATOS, Panayotis (eds). Federalism and International Relations: The Role of Subnational Units, pp.1-33, 1990.

FOLHAPRESS. Transferência de tecnologia de vacinas ao Brasil pode demorar até dez anos. In: Valor, 22/10/2020. Disponível em: < https://valor.globo.com/empresas/noticia/2020/10/22/transferencia-de-tecnologia-devacinas-ao-brasil-pode-demorar-ate-dez-anos.ghtml> Acessado em 06 de janeiro de 2021.

G1. Datafolha: $\mathbf{5 1 \%}$ reprovam desempenho de Bolsonaro na pandemia; $\mathbf{2 1 \%}$ aprovam. 14/05/2021. Disponível em <https://g1.globo.com/politica/noticia/2021/05/14/datafolha- 
51percent-reprovam-desempenho-de-bolsonaro-na-pandemia-21percent-aprovam.ghtml> Acessado em 24 de maio de 2021.

GIELOW, Igor. Datafolha: Lula amplia vantagem sobre Bolsonaro para 2022 e marca $58 \%$ a $31 \%$ no 2 o turno. In: Folha de São Paulo, 09/07/2021. Disponível em <https://www1.folha.uol.com.br/poder/2021/07/datafolha-lula-amplia-vantagem-sobrebolsonaro-para-2022-e-marca-58-a-31-no-2o-turno.shtml> Acessado em 10 de julho de 2021.

GOVERNO DO ESTADO DE SÃO PAULO. Governo de SP cria acordo para redução de emissão de gases do efeito estufa. 29/11/2019. Ano: 2019a. Disponível em: < https://cetesb.sp.gov.br/blog/2019/11/29/governo-de-sp-cria-acordo-para-reducao-deemissao-de-gases-do-efeito-estufa-e-acoes-de-sustentabilidade/> Acessado em 06 de janeiro de 2021.

GOVERNO DO ESTADO DE SÃO PAULO. Missão China 2019 embarca para Pequim em busca de negócios e investimentos. 02/08/2019. Ano: 2019b. Disponível em: <

https://www.investe.sp.gov.br/noticia/missao-china-2019-embarca-para-pequim-em-buscade-negocios-e-

investimentos/\#: :text=Um\%20dos\%20principais\%20objetivos\%20da,de\%20investimento\%2 Odispon\%C3\%ADveis\%20no\%20Estado.\&text=Al\%C3\%A9m\%20da\%20busca\%20por\%20inves timentos,Estado\%20com\%200\%20mercado\%20chin\%C3\%AAs.> Acessado em 06 de janeiro de 2021.

GOVERNO DO ESTADO DE SÃO PAULO. Governo de SP anuncia 1 escritório comercial de São Paulo na China. 02/04/2019. Ano: 2019c. Disponível em: < https://www.saopaulo.sp.gov.br/sala-de-imprensa/release/governo-de-sp-anuncia-1oescritorio-comercial-de-sao-paulo-na-china/> Acessado em 06 de janeiro de 2021.

GOVERNO DO ESTADO DE SÃO PAULO. Com 10,8 milhões de doses, Estado de SP garante estoque para iniciar vacinação. 30/12/2020. Ano: 2020. Disponível em: < https://www.saopaulo.sp.gov.br/noticias-coronavirus/com-108-milhoes-de-doses-estadode-sp-garante-estoque-para-iniciar-vacinacao/> Acessado em 06 de janeiro de 2021.

INSTITUTO BUTANTAN. Governo de SP assina contrato com Sinovac para o fornecimento de 46 milhões de doses da Coronavac. 30/09/2020. Disponível em: < https://butantan.gov.br/noticias/governo-de-sp-assina-contrato-com-sinovac-para-ofornecimento-de-46-milhoes-de-doses-da-coronavac> Acessado em 06 de janeiro de 2021.

JUBÉ, Andrea. O “diplomata” da Amazônia Legal. In: Valor, 29/12/2020. Disponível em < https://valor.globo.com/google/amp/politica/coluna/o-diplomata-da-amazonialegal.ghtml? twitter impression=true> Acessado em 05 de janeiro de 2021. 
JUNQUEIRA, Cairo. Acordo define que Butantan custeia Coronavac, mas sem propriedade intelectual. In: CNN. 11/11/2020. Disponível em: < https://www.cnnbrasil.com.br/saude/2020/11/11/acordo-define-que-butantan-custeiacoronavac-mas-sem-direito-intelectual> Acessado em 06 de janeiro de 2021.

KEATING, Michael. Regiones y Asuntos Internacionales: Motivos, Oportunidades y Estrategias. In: ALDECOA, F.; KEATING, M. (eds.). Paradiplomacia: Las Relaciones Internacionales de las Regiones. Madrid/Barcelona: Marcial Pons, 2001.

KHALIL, Suhayla. Muito além da vacina. In: Estadão, 21/06/2020. Disponível em < https://politica.estadao.com.br/blogs/fausto-macedo/muito-alem-da-vacina/> Acessado em 06 de janeiro de 2021.

MARINGONI, Gilberto.; SHUTTE, Giorgio R; BERRINGER, Tatiana (Org). As bases bolsonaristas da política externa brasileira. Santo André: EdUFABC, 2021. Disponível em:

https://editora.ufabc.edu.br/images/Livros/Bases da_politica_externa_bolsonarista.pdf

MASSOT, Affonso. Entrevista [janeiro de 2021]. Entrevistadora: Ana Tereza L. M. de Sousa. São Paulo, 2021.

MEDEIROS, Marcelo de Almeida. ¿Necesita São Paulo Una Política Exterior? Hegemonía, Diplomacia Y Paradiplomacia en Brasil. In: América Latina Hoy, 56, 2010, pp. 163-186. Disponível em: < https://revistas.usal.es/index.php/1130-2887/article/view/7790/7799> Acessado em 06 de janeiro de 2021.

MIKLOS, Manoela. A inserção internacional de unidades subnacionais percebida pelo estado nacional: a experiência brasileira. Dissertação (Mestrado em Relações Internacionais). Programa de Pós-Graduação em Relações Internacionais San Tiago Dantas (Unesp, Unicamp e PUC-SP), São Paulo, 2010.

MILANI, Carlos R. S.; PINHEIRO, Letícia (Org.). Política Externa Brasileira. As práticas da política e a política das práticas. Rio de Janeiro: FGV, 2012.

MONTEIRO, Daniel. Começam Obras Da Nova Fábrica Do Butantan Para Produção Da Vacina Coronavac. 09/11/2020. Disponível em: < https://www.saopaulo.sp.leg.br/coronavirus/blog/comecam-obras-da-nova-fabrica-dobutantan-para-producao-da-vacina-coronavac/> Acessado em 06 de janeiro de 2021.

MOREIRA, Assis. Confusão do governo prejudica compras de equipamentos da China. In: Valor, 20/05/2020. Disponível em:

<https://valor.globo.com/brasil/noticia/2020/05/20/confusao-do-governo-prejudicacompras-de-equipamentos-contra-covid-19.ghtml> Acessado em 06 de janeiro de 2021. 
MOTTA, Daniel. TCE cobra esclarecimentos do governo de SP por contrato com a chinesa Sinovac. In: CNN, 24/07/2020. Disponível em:

$<$ https://www.cnnbrasil.com.br/nacional/2020/07/24/tce-cobra-esclarecimentos-dogoverno-de-sp-por-contrato-com-a-chinesa-sinovac> Acessado em 06 de janeiro de 2021.

MURAKAWA, Fábio. Pazuello bate-boca com Doria em reunião com governadores. In: Valor. 08/12/2020. Disponível em: <https://valor.globo.com/politica/noticia/2020/12/08/pazuellobate-boca-com-doria-em-reunio-com-governadores.ghtml> Acessado em 06 de janeiro de 2021.

OLIVEIRA, Vanessa Elias de; RODRIGUES, G. M. A. Brazil and Covid-19: The President against the Federation, UACES Territorial Politics, 5 de junho de 2020. Disponível em:

https://uacesterrpol.wordpress.com/2020/06/05/brazil-and-covid-19-the-president-againstthe-federation/>

PINHONI, Marina; FIGUEIREDO, Patrícia. Governo federal não liberou verba para vacina chinesa em SP e só investiu na de Oxford, diz secretário. In: G1, 14/10/2020. Disponível em: < https://g1.globo.com/sp/sao-paulo/noticia/2020/10/14/governo-federal-nao-liberouverba-para-vacina-chinesa-em-sp-e-so-investiu-na-de-oxford-diz-secretario.ghtml> Acessado em 06 de janeiro de 2021.

PRADO, Debora F. M. A atuação internacional dos governos subnacionais: construções conceituais, limites e contribuições para o caso brasileiro. Carta Internacional, Vol. 13, n. 3, 2018. Disponível em:

http://cartainternacional.abri.emnuvens.com.br/Carta/article/view/846

RODRIGUES, Gilberto Marcos Antonio. Relações internacionais federativas no Brasil. In: Dados, vol.51 no.4 Rio de Janeiro, 2008. Disponível em < https://www.scielo.br/scielo.php?script=sci_arttext\&pid=S0011-52582008000400007> Acessado em 06 de janeiro de 2021.

RODRIGUES, Gilberto Marcos Antonio. Será a hora e a vez da paradiplomacia para estados e municípios? In: Carta Capital, 17/08/2019. Disponível em < https://www.cartacapital.com.br/blogs/observamundo/sera-a-hora-e-a-vez-daparadiplomacia-para-estados-e-municipios/> Acessado em 06 de janeiro de 2021.

SANTORO, Maurício. Crises provocadas por Bolsonaro abrem espaço para governadores na diplomacia. In: Época, 01/09/2019. Disponível em < https://epoca.globo.com/brasil/artigocrises-provocadas-por-bolsonaro-abrem-espaco-para-governadores-na-diplomacia$23914293>$ Acessado em 06 de janeiro de 2021.

SCHUTTE, Giorgio Romano. Oasis para o capital: solo fértil para a corrida de ouro - a dinâmica dos investimentos produtivos chineses no Brasil. São Paulo: Appris, 2020. 
SERSON, Júlio. [Entrevista concedida a] Marina Lang. In: Diálogo Chino, 13/08/2020. Disponível em: < https://dialogochino.net/en/trade-investment/36888-brazils-stategovernors-open-their-own-channels-with-china/> Acessado em 06 de janeiro de 2021.

SOLDATOS, Panayotis. Cascading Subnational Paradiplomacy in an Interdependent and Transnational World. In: BROWN, Douglas; FRY, Earl (Ed.). States and provinces in the international economy. California: Institute of Governmental Studies Press, University of California, 1993. p. 45-64.

SOUSA, A.T.; BELASQUES, B.; CASTRO, B.; CARNEIRO, G.; ABRÃO, R.; SANTOS, V. H. Relações Brasil-China durante a pandemia: abalos no pragmatismo. In: AZZI, Diego; RODRIGUES, Gilberto M. A.; SOUSA, Ana Tereza L. M. (Orgs). A política externa de Bolsonaro na pandemia. São Bernardo do Campo: OPEB/FES, 2020.

TAVARES, Rodrigo. As Relações Internacionais do Estado de São Paulo. Revista Política Externa, Vol. 20, n. 4, Mar-Maio, 2012, p. 169-184.

TAVARES, Rodrigo. As Relações Internacionais do Estado de São Paulo. In: MARCOVITH, Jacques; DALLARI, Pedro (Org.). Relações Internacionais em Âmbito Subnacional: A Experiência de Estados e Municípios no Brasil. São Paulo: IRI/USP, 2014, p. 12-27.

TEIXEIRA, Jerônimo. O Dia Em Que O Presidente Comemorou Um Suicídio. In: Época, 12/11/2020. Disponível em: <https://epoca.globo.com/jeronimo-teixeira/coluna-o-dia-emque-presidente-comemorou-um-suicidio-24742482> Acessado em 06 de janeiro de 2021.

VALOR. Frente de Prefeitos também pede a saída de Ernesto Araújo, 26.03.2021. Disponível em: https://valor.globo.com/politica/noticia/2021/03/26/frente-de-prefeitos-tambempede-a-saida-de-ernesto-araujo.ghtml (Acesso em 14.05.2021).

VELASCO, Clara. Especialistas apontam falta de coordenação federal na compra de respiradores por parte dos estados. In: G1, 26/09/2020. Disponível em: <https://g1.globo.com/bemestar/coronavirus/noticia/2020/06/29/especialistas-apontamfalta-de-coordenacao-federal-na-compra-de-respiradores-por-parte-dos-estados.ghtml> Acessado em 06 de janeiro de 2021.

VIGEVANI, Tullo. Problemas para a atividade internacional das unidades subnacionais. Estados e municípios brasileiros. In: Revista Brasileira de Ciências Sociais, v. 21, 2006.

XINHUA. Governo do estado de São Paulo assina acordo com farmacêutica chinesa Sinovac para vacina contra coronavírus. 12/06/2020. Disponível em: < http://portuguese.xinhuanet.com/2020-06/12/c 139133577.htm > Acessado em 06 de janeiro de 2021. 